\title{
Becoming a high impact journal
}

\author{
Gheun-Ho Kim \\ Department of Internal Medicine, Hanyang University College of Medicine, Seoul, Republic of Korea
}

"Publish or perish." Scientists are eager to publish their work to be recognized by others in their field. These achievements are closely connected to promotion in academic societies and to financial support for further research. Thus, physician scientists are always on the lookout for a good venue to publish their findings.

Peer-reviewed journals are the most representative formal pathway of publication in medical research. They are rapidly increasing in number, especially with the emergence of online/web publishing. Consequently, scientific medical journals have to compete with one another to publish high quality articles. Authors and readers also need to be cautious about junk publishers and/or predatory journals [1].

How do we recognize decent journals and articles? Citation indexes between publications have been used to indicate the quality of an article or journal, with impact growing as the number of citation increases. Scopus and Journal Citation Reports (Web of Science) are the major global citation databases, and they annually calculate citation indices in the form of CiteScore and Journal Impact Factor, respectively. To have a citation index, the journal has to be listed in Scopus and Journal Citation Reports. For this, the journal must pass an evaluation and

Received November 16, 2020; Accepted November 19, 2020

Editor: Tae-Hyun Yoo, Yonsei University, Seoul, Republic of Korea Correspondence: Gheun-Ho Kim

Department of Internal Medicine, Hanyang University College of Medicine, 222-1 Wansimni-ro, Seongdong-gu, Seoul 04763, Republic of Korea. E-mail: kimgh@hanyang.ac.kr

Copyright (C) 2020 by The Korean Society of Nephrology

(a) This is an open-access article distributed under the terms of the Creative Commons Attribution Non-Commercial License (http://creativecommons. org/licenses/by-nc-nd/4.0/), which permits unrestricted non-commercial use, distribution, and reproduction in any medium, provided the original work is properly cited. selection process based on timeliness, editorial conventions, peer review, citation, and international diversity or geographic representation [2,3].

Kidney Research and Clinical Practice, the official journal of the Korean Society of Nephrology, was originally launched in 1982 as a domestic publication (The Korean Journal of Nephrology) and was published as a full English version from the first issue of 2012, in order to globally expand our readership by reaching an international level of quality. First, we renamed our journal to cover both basic science and clinical nephrology. A new website was prepared for readers to have a free access to our journal. Electronic submission and peer review systems were developed. Our editorial board comprised domestic and international members with substantial academic achievements.

However, English editing was a challenge for our editorial staff because English was not their native tongue. To maintain the highest level of editorial conventions, multiple editing processes were set up using our own styles. Authors were encouraged to use professional language editing services prior to submission. During our review processes, we checked the grammar and style as well as the scientific quality. After acceptance, manuscripts undergo editing by another professional English-language editing and proofreading service before the author proof stage. Ethical standards for publication were also considered.

With these efforts, Kidney Research and Clinical Practice was listed in Scopus in its early phases. According to the CiteScore, we ranked the 19th among 59 nephrology journals listed in Scopus in 2019. Our updated CiteScore was 4.4 on November 8, 2020, representing a major leap. Fig. 1 shows the trend of CiteScore, SCImago Journal Rank, and Journal Impact Factor from 2017 to 2019.

Consistent with this, we received good news from the 


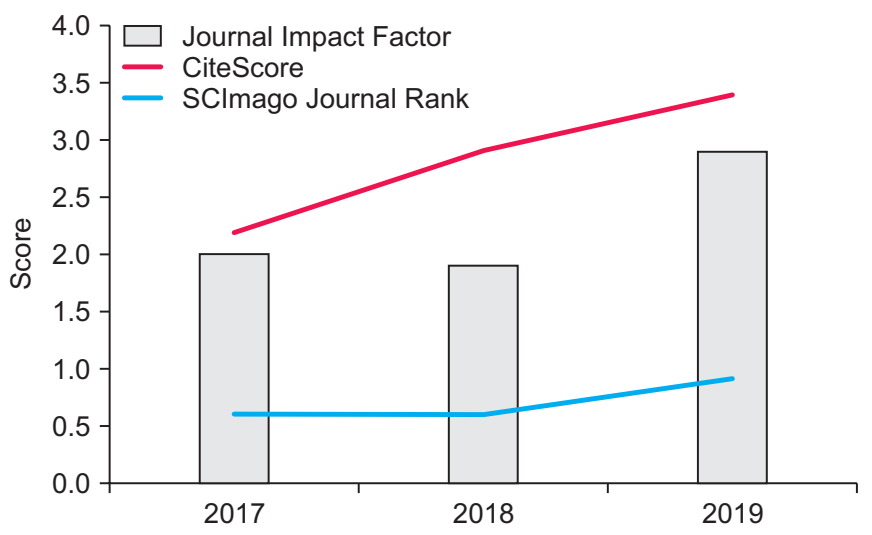

Figure 1. Journal metrics of Kidney Research and Clinical Practice (KRCP) shows the trend of Journal Impact Factor, CiteScores, and SCImago Journal Rank from 2017 to 2019. The Journal Impact Factors were informally calculated by the editorial board of KRCP.

Web of Science that Kidney Research and Clinical Practice was selected for coverage in the Science Citation Index Expanded (SCIE) and Current Contents/Clinical Medicine (Urology \& Nephrology) on November 4, 2020. This coverage in SCIE is underway, beginning with articles published since 2018. Our Journal Impact Factor, which was informally calculated at the end of 2019, was 2.89. It is expected to exceed 3.0 this year.

In accordance with the second stage of Kidney Research and Clinical Practice, our editorial board was updated to reflect the needs of a high impact journal. The new editor-in-chief and younger editors will devote themselves to recruiting high quality articles and to producing well-crafted publications. International members of the editorial board will also play a more active role, and more international reviewers will be recruited to participate in our peer review process.

East Asia including China, Taiwan, Japan, and South Korea has a high burden of kidney failure compared with other areas of the world. A large number of patients are undergoing kidney replacement therapy, and the cost is enormous [4]. East Asian physician scientists are thus very active in kidney research and publish many papers in high impact journals. I hope that Kidney Research and Clinical Practice continues to be a well-reputed venue for sharing their academic results with a global readership and for helping translate their advancements in knowledge into clinical practice.

\section{Conflicts of interest}

The author has no conflicts of interest to declare.

\section{References}

[1] Kebede M, Schmaus-Klughammer AE, Tekle BT. Manuscript submission invitations from 'predatory journals': what should authors do? J Korean Med Sci 2017;32:709-712.

[2] Clarivate Analytics. ISI Web of knowledge ${ }^{\mathrm{SM}}$ [Internet]. Philadelphia (USA): Thomson Reuters, c2008 [cited 2020 Nov 12]. Available from: https://web.archive.org/ web/20101123014042/https://www.thomsonreuters.com/ content/science/pdf/Web_of_Knowledge_factsheet.pdf.

[3] Elsevier. Content - how Scopus works [Internet]. Amsterdam (Nederland): Elsevier, c2013 [cited 2020 Nov 12]. Available from: https://www.elsevier.com/solutions/scopus/ how-scopus-works/content\#content-policy-and-selection.

[4] Tang SCW, Yu X, Chen HC, et al. Dialysis care and dialysis funding in Asia. Am J Kidney Dis 2020;75:772-781. 